\title{
Development of Mathematical Supply Chain Model for Challenges in E-Commerce Distribution
}

\author{
C. Pradeepkumar, S. Karthikeyan, N. Jawahar, S. Aravind Raj, N. Rajini
}

\begin{abstract}
Recent supply chain faces numerous issues while addressing factors related to online markets, such as fast and secured deliveries to the customers. Even most of the $E$ commerce businesses have their own logistics and warehousing network, the real time challenges may occur with respect to routing, inventory and fast delivery to the customer in this internet era. This work addresses the issue in supply chain for E-commerce by developing a suitable mathematical model and applying with real time working conditions which tends to give a suitable solution for the problem.
\end{abstract}

Keywords: Supply chain, E-Commerce, Mathematical model Introduction

\section{INTRODUCTION}

A supply chain is the machine of groups, people, activities, information, and sources worried in moving a product or service from supplier to client. Supply chain activities involve the transformation of natural sources, uncooked materials, and components right into a finished product this is added to the stop patron. In state-of-the-art supply chain systems, used merchandise can also re-enter the supply chain at any point in which residual fee is recyclable. The position of distribution within the supply chain management model has extended considerably from the conventional view of the activity as being concerned entirely with transport and warehousing. The crucial undertaking that underlies a success distribution nowadays is demand management. The critical task that underlies successful distribution today is demand management. The rapid improvement in information era has allowed many business corporations to construct linkages and accelerate statistics go together with the waft and sharing with others in their supply chains. In

Revised Manuscript Received on December 05, 2019.

* Dr. S. Karthikeyan

C.PradeepKumar*, Research Scholar, Department of Automobile Engineering, Kalasalingam University, Krishnan Koil, Virudhunagar, Tamilnadu, India - 626126. Email: pradeep93smart@gmail.com

Dr. S. Karthikeyan, Associate Professor, Department of Automobile Engineering, Kalasalingam University, Krishnan Koil, Virudhunagar, Tamilnadu, India - 626126. Email: scorthik@gmail.com

Dr. N. Jawahar, Professor, Department of Mechanical Engineering, Ramco Institute of Technology, Rajapalayam, Virudhunagar, Tamilnadu, India - 626117. Email: jawahar@tce.edu

Dr. S. Aravind Raj, Associate professor, Department of Mechanical Engineering, Vellore Institute of Technology, Katpadi, Vellore, Tamilnadu, India - 632014. Email: aravindsakthivel@ hotmail.com

Dr. N. Rajini, Professor, Department of Mechaical Engineering, Kalasalingam University, Krishnan Koil, Virudhunagar, Tamilnadu, India 626126. Email: rajiniklu@gmail.com particular, Electronic Business (EB) technologies facilitate the interplay between corporations and their companies for the cause of converting information which incorporates purchase orders, invoices and payments. For instance, Do It Best Corp., a distributor of hardware and building merchandise, has been effective in the use of EC era for purchase ordering, invoicing, scheduling and remittance operations. Peapod, a US meals retailer, is using the net medium, and affords its clients with a homepurchasing provider through the Internet.

\section{A. E-Commerce Supply Chain Strategies}

Percentage of on line sales compared to in-shop income maintains to upward thrust, and multichannel retailers supply chain techniques need to maintain pace. Those engaged in e-commerce have extra options all the time.

Here are ten opportunities to take into account:

1. Internet customers count on quicker delivery, and having multiple distribution points can offer enhance shipping times.

2. Being in the direction of the customer can result in outbound freight financial savings.

Three. There may be benefits to processing imports in a western distribution center. The blessings can be cost or time

4. If DCs which can be close to home carriers can obtain inbound freight financial savings. You can get hold of product from a seller within the closest facility and redistribute it.

5. There is a good hard work marketplace. Multiple DCs permit the splitting of hard work swimming pools.

6. Redundancy of operations can offer continuity backup in trade for doubtlessly duplicated overhead rate.

7. There may be nearby incentives to be had for relocation.

8. Overall stock control will enhance out of necessity because of doubtlessly improved inventory stages.

9. As the direct-to-customer base increases, it must offer elevated liquidation opportunities.

10. It is a good deliver chain approach for multichannel retailers to capitalize on the synergy of different channels and meet the expectancy of customers whether or not directto-purchaser or retail this is, provided multichannel outlets develop their infrastructure of facilities and order control structures.

\section{LITERATURE REVIEW}

Cui et al (2015) present a singular joint replenishment and synthetical shipping (JRP) version is proposed to enhance the coordination

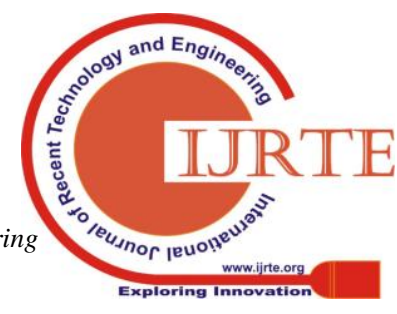


replenishment and shipping techniques. Traditional, in a warehouse centralized deliver chain, order from online clients are generally delivered independently after multiple objects had been at the time replenished. [1] To decrease the outbound shipping valve, a brand-new shipping approach thinking about synthetical dispatched orders, and customers matching, and purchaser journeying series is proposed.

Salameh et al (2014) gift a joint replenishment model (JRM) is used to decide most appropriate stock stages, in which the quantity to order (for each item) is designed to limit the joint maintaining and ordering costs based totally on a given demand. [2] This paper combines the separate works on substitution and joint replenishment and proposes an answer method for fixing the joint replenishment version with substitution (JRMS) for two merchandise inside the framework of the classical economic order quantity version. Amayan et al (2013) [3] gift clear up the joint replenishment problem beneath deterministic call for and resource constraints (C-JRP). A heuristic framework primarily based on linear programming is presented. [4] Moshe et al (2012) gift joint replenishment for numerous merchandises to gain a lower stock logistics price has been a subject of huge studies. Less interest has been paid to the problem of finding out how the joint replenishment charges should be allocated throughout the individual products. Ideally, whilst items are ordered together one could require a strong value allocation, such that no subset of products subsidizes every other subset. [5][6] This paper affords main insights for determining the precise cost allocation. It provides the approach to check how touchy a stable cost allocation is to a range of price parameter values. Then, in a computational examine, it is shown the way to obtain a strong price allocation without immoderate computation. [7][8] Wang et al. (2012) gift as an critical managerial hassle, the sensible joint replenishment and delivery (JRD) model under stochastic demand can be seemed because the combination of a joint replenishment trouble and traveling salesman trouble, both one is an NP-tough hassle.[9] However, because of the JRD's difficult mathematical residences, excessive pleasant answers for the problem have eluded researchers. [10] This paper first of all proposes an effective and green hybrid differential evolution set of rules (HDE) based at the differential evolution algorithm (DE) and genetic algorithm (GA) that may clear up this NP-difficult hassle in a strong and unique way.[11] After determining the suitable parameters of the HDE by way of parameters tuning take a look at, the effectiveness and efficiency of the HDE are proven by way of benchmark features and numerical examples. They compare the HDE with the available highquality technique and find that the HDE can constantly acquire the marginally decrease general prices underneath a few situations. [12] Compared with any other famous evolutionary set of rules, effects of numerical examples also show HDE is faster than GA and the convergence rate of HDE is better than GA. HDE is a sturdy candidate for the JRD underneath stochastic demand.

\section{A. Problem Description}

In E -commerce company, generally the customer orders the product. For that product there are many supplies are available. Among these, the customer can choose the supplier from whom he desires to purchase. In between the customer and supplier, the company behaves as the mediator. The product is collected by the receiving point, then the receiving point transfer's the product to the distribution point from there it meets to the customer. Here the supplier cannot delivery his product directly to the customer, and also the receiving point cannot deliver the product directly to the customer. The product sent to the customer via the receiving point, both distribution point and receiving point (hub), distribution point. For this environment the model layout is created and shown below.

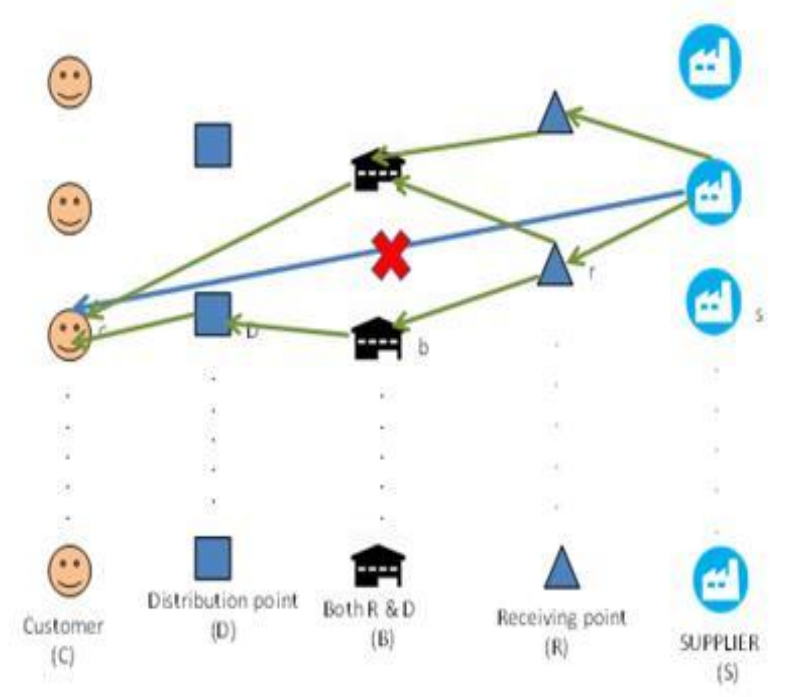

Fig. 1. Problem environment

In this model the customer has ordered the product from the supplier, the scenario represents the transaction of the product from the supplier to customer. For the single customer, the unrestricted capacity of routes and transaction points are solvable by shortest routing problem method. In practice, Routes - having limited capacity.

Transactions points - having limited handling capacity such as man power, storage, logistics providers. For this SRP is not possible for more customer say above 1000 . 


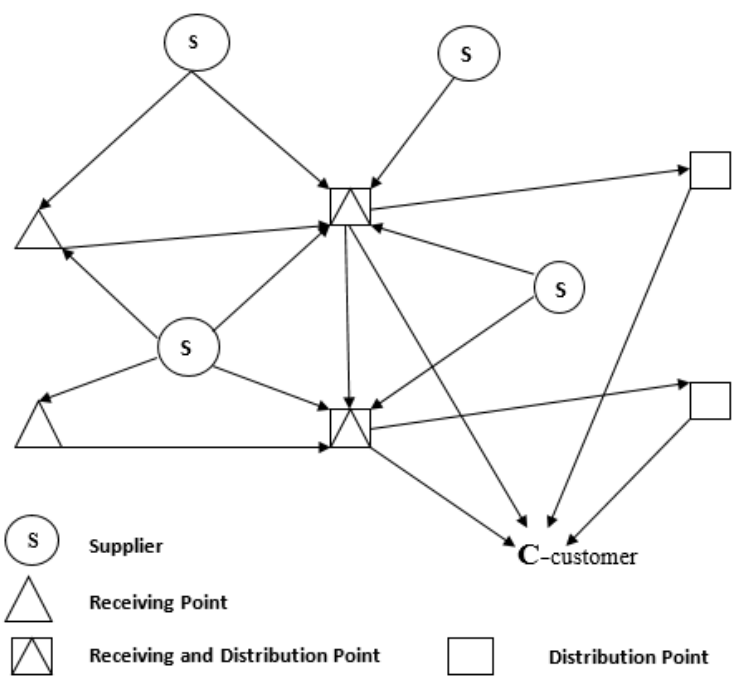

Fig. 2. Network of e-commerce supply chain

\section{MATHEMATICAL MODEL}

\section{A. Sets and Indices}

c- Index for customers $(c=1,2 \ldots C)$

$\mathrm{p}$ - Index for products $(\mathrm{p}=1,2 \ldots \mathrm{P})$

s- Index for suppliers $(\mathrm{s}=1,2 \ldots \mathrm{S})$

$\mathrm{r}$ - Index for receiving center $(\mathrm{r}=1,2 \ldots \mathrm{R})$

b- Index for both center $(r \& d)(b=1,2 \ldots B)$

$\mathrm{d}$ - Index for distribution center $(\mathrm{d}=1,2 \ldots \mathrm{D})$

\section{B. Model Parameters}

$A_{s p}=$ available of product ' $\mathrm{p}$ ' with the supplier 's'

$Y_{c p}=$ number of customer order for the products

$W_{p}=$ weight of the product

$T^{p}=$ transportation cost per unit $\mathrm{kg} / \mathrm{km}$

$H_{r}=$ capacity of the receiving center

$H_{b}=$ capacity of the both center

$H_{d}=$ capacity of the distribution center

$D_{s r}=$ distance between supplier and receiving center

$D_{s b}=$ distance between supplier and both center

$D_{r d}=$ distance between receiving and distribution center

$D_{b d}=$ distance between both and distribution center

$D_{d c}=$ distance between distribution and customer

$D_{r b}=$ distance between receiving and both center

$D_{b c}=$ distance between both center and customer

\section{Objective Function}

Total cost of transportation is to be minimum, for that there are many number of routes are available. For minimum TC the shortest route will be chosen.

Minimize $T C=f($ route $\&$ suppliers $)$

$$
\begin{aligned}
\sum_{c=1}^{c} \sum_{p=1}^{P} Y_{c p} T^{p} & W_{P}\left(\sum_{s=1}^{S} S_{s}^{p c} \sum_{r=1}^{R} R_{r}^{p c} D_{s r}+\sum_{s=1}^{S} S_{s}^{p c} \sum_{b=1}^{-\bar{B}} B_{b}^{p c} D_{s b}+\sum_{r=1}^{R} R_{r}^{p c} \sum_{d=1}^{D} D_{d}^{p c} D_{r d}\right. \\
+ & \left.\sum_{r=1}^{R} R_{r}^{p c} \sum_{b=1}^{B} B_{b}^{p c} D_{r b}+\sum_{b=1}^{B} B_{b}^{p c} \sum_{d=1}^{D} D_{d}^{p c} D_{b d}+\sum_{b=1}^{B} B_{b}^{p c} D_{b c}+\sum_{d=1}^{D} D_{d}^{p c} D_{d c}\right\}
\end{aligned}
$$

\section{Subjected to be Constraints}

$$
\begin{gathered}
\sum_{s=1}^{S} S_{s}^{p c}\left\{\left[\sum_{r=1}^{R} R_{r}^{p c}\left\{\sum_{d=1}^{D} D_{d}^{p c}\left(1-\sum_{b=1}^{B} B_{b}^{p c}\right)\right\}+\sum_{b=1}^{B} B_{b}^{p c}\left\{\left(1-\sum_{d=1}^{D} D_{d}^{p c}\right)+\sum_{d=1}^{D} D_{d}^{p c}\right\}\right]+\left[\sum_{b=1}^{B} B_{b}^{p c}(1\right.\right. \\
\left.\left.\left.-\sum_{r=1}^{R} R_{r}^{p c}\right)\left\{\left(1-\sum_{d=1}^{D} D_{d}^{p c}\right)+\sum_{d=1}^{D} D_{d}^{p c}\right\}\right]\right\}=1 \quad \forall p, \forall c
\end{gathered}
$$

$$
\begin{aligned}
& \sum_{s=1}^{S} S_{s}^{p c} A_{S P}=1 \quad \forall p, \forall c \\
& \sum_{r=1}^{R} R_{r}^{p c} \leq 1 \forall p, \forall c \\
& \sum_{b=1}^{B} B_{b}^{p c} \leq 1 \quad \forall p, \forall c
\end{aligned}
$$

$$
\sum_{d=1}^{D} D_{d}^{p c} \leq 1 \forall p, \forall c
$$

$$
\sum_{r=1}^{R} R_{r}^{p c}+\sum_{b=1}^{B} B_{b}^{p c} \geq 1 \forall p, \forall c
$$

$$
\sum_{r=1}^{R} R_{r}^{p c}+\sum_{b=1}^{B} B_{b}^{p c} \leq \forall 2 \forall p, \forall c
$$

$\sum_{d=1}^{D} D_{d}^{p c}+\sum_{b=1}^{B} B_{b}^{p c} \geq 1 \forall p, \forall c$

$$
\sum_{d=1}^{D} D_{d}^{p c}+\sum_{b=1}^{B} B_{b}^{p c} \leq 2 \forall p, \forall c
$$

$\sum_{p=1}^{P} \sum_{c=1}^{c} \sum_{s=1}^{S} S_{s}^{p c} R_{r}^{p c}+\left(\sum_{p=1}^{P} \sum_{s=1}^{S} \sum_{b=1}^{B} B_{b}^{p c} R_{r}^{p c}+\sum_{p=1}^{P} \sum_{s=1}^{S} \sum_{d=1}^{D} D_{d}^{p c} R_{r}^{p c}\right) \leq H_{\mathrm{r}} \forall r$

$$
\left(\sum_{p=1}^{P} \sum_{c=1}^{c} \sum_{s=1}^{S} S_{s}^{p c} B_{b}^{p c}+\sum_{p=1}^{P} \sum_{s=1}^{S} \sum_{r=1}^{R} R_{r}^{p c} B_{b}^{p c}+\sum_{p=1}^{P} \sum_{s=1}^{S} \sum_{d=1}^{D} D_{d}^{p c}+\sum_{p=1}^{P} \sum_{s=1}^{S} B_{b}^{p c}\right) \leq H_{\mathrm{b}} \forall b
$$

$\sum_{p=1}^{P} \sum_{c=1}^{c} \sum_{r=1}^{R} R_{r}^{p c} D_{d}^{p c}+\left(\sum_{p=1}^{P} \sum_{s=1}^{S} \sum_{b=1}^{B} B_{b}^{p c} D_{d}^{p c}+\sum_{p=1}^{P} \sum_{s=1}^{S} D_{d}^{p c}\right) \leq H_{\mathrm{d}} \forall d$

\section{COMBINATIONS}

\section{A. Model Illustration}

In this model there are ten number of customers who order their product from seven number of suppliers in between them there are five number of receiving point and four number of distribution point and both (receiving point and distribution point). For 
this scenario the distance/ cost matrix is developed and solved by the shortest routing problem and constrains are added to this model.

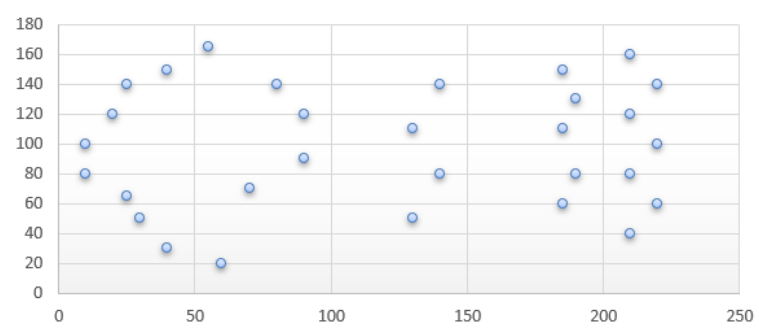

Fig. 3. Distance/cost between customer \& supplier

\section{B. Distance/ cost Matrix}

Table-I: Distance/cost Matrix

\begin{tabular}{|cc|c|c|}
\hline NODES & $X_{i}$ & $Y_{i}$ \\
\hline Customerc c & 1 & 20 & 120 \\
& 2 & 25 & 140 \\
3 & 10 & 100 \\
4 & 10 & 80 \\
5 & 25 & 65 \\
6 & 30 & 50 \\
7 & 40 & 30 \\
8 & 60 & 20 \\
9 & 40 & 150 \\
10 & 55 & 165 \\
\hline Suppliers & 1 & 210 & 160 \\
2 & 220 & 140 \\
3 & 210 & 120 \\
4 & 220 & 100 \\
5 & 210 & 80 \\
6 & 220 & 60 \\
7 & 210 & 40 \\
\hline
\end{tabular}

Table- II: Distance/cost Matrix

\begin{tabular}{|cc|c|c|}
\hline \multicolumn{2}{|c|}{ NODE } & $X_{i}$ & $Y_{i}$ \\
\hline Receiving point r & 1 & 185 & 150 \\
& 2 & 190 & 130 \\
& 3 & 185 & 110 \\
& 4 & 190 & 80 \\
& 5 & 185 & 60 \\
\hline Both (R\&D) b & 1 & 140 & 140 \\
& 2 & 130 & 110 \\
& 3 & 140 & 80 \\
& 4 & 130 & 50 \\
\hline Distribution point d & 1 & 80 & 140 \\
& 2 & 90 & 120 \\
& 3 & 90 & 90 \\
& 4 & 70 & 70 \\
\hline
\end{tabular}

The trouble of finding the shortest route amonst the points on the road map can be modeled as a uniqe case of the shortest direction hassle in graphs, in which the vertices correspond to points and the side correspond to road segments, every weighted with the resource of the length of the phase.

\section{SRP Solutions}

Table-III: SRP Solution table

\begin{tabular}{|c|c|c|}
\hline Customer order & SRP Routes & Min cost \\
\hline$c_{1}-S_{2}$ & $s_{2}-r_{1}-b_{1}-c_{1}$ & 204.14 \\
\hline $\mathrm{C}_{2}-\mathrm{S}_{3}$ & $s_{3}-r_{2}-b_{1}-c_{2}$ & 188.35 \\
\hline $\mathrm{C}_{3}-\mathrm{S}_{4}$ & $s_{4}-r_{3}-b_{2}-c_{3}$ & 211.81 \\
\hline$C_{4}-S_{1}$ & $s_{1}-r_{1}-b_{1}-c_{4}$ & 216.18 \\
\hline $\mathrm{C}_{5}-\mathrm{S}_{7}$ & $s_{7}-r_{5}-b_{4}-c_{5}$ & 193.97 \\
\hline $\mathrm{C}_{6}-\mathrm{S}_{6}$ & $s_{6}-r_{5}-b_{4}-c_{6}$ & 190.90 \\
\hline $\mathrm{C}_{7}-\mathrm{S}_{6}$ & $s_{6}-r_{5}-b_{4}-c_{7}$ & 183.09 \\
\hline $\mathrm{C}_{8}-\mathrm{S}_{5}$ & $s_{5}-r_{4}-b_{3}-c_{8}$ & 155.44 \\
\hline $\mathrm{C}_{9}-\mathrm{S}_{3}$ & $s_{3}-r_{2}-b_{1}-c_{9}$ & 173.84 \\
\hline$c_{10}-S_{1}$ & $s_{1}-r_{1}-b_{1}-c_{10}$ & 161.61 \\
\hline
\end{tabular}

\section{Some Feasible Solutions (Identified Arbitrarily)} SOLUTION -1

$$
\begin{array}{ll}
\mathrm{s}_{2}-\mathrm{r}_{1}-\mathrm{b}_{1}-\mathrm{d}_{1}-\mathrm{c}_{1}=205.73 \\
\mathrm{~s}_{3}-\mathrm{r}_{2}-\mathrm{b}_{1}-\mathrm{d}_{2}-\mathrm{c}_{2}=195.20 \\
\mathrm{~s}_{4}-\mathrm{r}_{3}-\mathrm{b}_{2}-\mathrm{d}_{3}-\mathrm{c}_{3}=216.74 \\
\mathrm{~s}_{1}-\mathrm{r}_{3}-\mathrm{b}_{2}-\mathrm{c}_{4}=234.59 \\
\mathrm{~s}_{7}-\mathrm{r}_{5}-\mathrm{b}_{3}-\mathrm{d}_{4}-\mathrm{c}_{5}=197.23 \\
\mathrm{~s}_{6}-\mathrm{r}_{5}-\mathrm{b}_{3}-\mathrm{c}_{6}=198.25 \\
\mathrm{~s}_{6}-\mathrm{r}_{4}-\mathrm{b}_{4}-\mathrm{c}_{7}=195.30 \\
\mathrm{~s}_{5}-\mathrm{r}_{4}-\mathrm{b}_{4}-\mathrm{c}_{8}=163.23 \\
\mathrm{~s}_{3}-\mathrm{r}_{2}-\mathrm{b}_{2}-\mathrm{c}_{9}=184.08 \\
\mathrm{~s}_{1}-\mathrm{r}_{1}-\mathrm{b}_{1}-\mathrm{c}_{10}=161.60
\end{array}
$$

$$
\sum \Rightarrow 1951.8
$$

\section{SOLUTION -2}

$$
\begin{array}{lc}
\mathrm{s}_{2}-\mathrm{r}_{2}-\mathrm{b}_{1}-\mathrm{d}_{2}-\mathrm{c}_{1}=206.46 \\
\mathrm{~s}_{3}-\mathrm{r}_{2}-\mathrm{b}_{2}-\mathrm{d}_{1}-\mathrm{c}_{2}=198.90 \\
\mathrm{~s}_{4}-\mathrm{r}_{3}-\mathrm{b}_{2}-\mathrm{c}_{3}=211.81 \\
\mathrm{~s}_{1}-\mathrm{r}_{1}-\mathrm{b}_{1}-\mathrm{d}_{3}-\mathrm{c}_{4}=224.34 \\
\mathrm{~s}_{7}-\mathrm{r}_{5}-\mathrm{b}_{3}-\mathrm{c}_{5}=197.22 \\
\mathrm{~s}_{6}-\mathrm{r}_{4}-\mathrm{b}_{4}-\mathrm{d}_{4}-\mathrm{c}_{6}=211.09 \\
\mathrm{~s}_{6}-\mathrm{r}_{5}-\mathrm{b}_{3}-\mathrm{c}_{7}=196.64 \\
\mathrm{~s}_{5}-\mathrm{r}_{4}-\mathrm{b}_{3}-\mathrm{c}_{8}=155.44 \\
\mathrm{~s}_{3}-\mathrm{r}_{3}-\mathrm{b}_{1}-\mathrm{c}_{9}=181.49 \\
\mathrm{~s}_{1}-\mathrm{r}_{1}-\mathrm{b}_{2}-\mathrm{c}_{10}=187.92
\end{array}
$$<smiles>C1CCCC1</smiles> 


\section{SOLUTION -3}

$$
\begin{array}{lc}
\mathrm{s}_{2}-\mathrm{r}_{1}-\mathrm{b}_{2}-\mathrm{c}_{1} & =202.75 \\
\mathrm{~s}_{3}-\mathrm{r}_{2}-\mathrm{b}_{1}-\mathrm{c}_{2} & =188.35 \\
\mathrm{~s}_{4}-\mathrm{r}_{3}-\mathrm{b}_{2}-\mathrm{d}_{1}-\mathrm{c}_{3} & =230.32 \\
\mathrm{~s}_{1}-\mathrm{r}_{2}-\mathrm{b}_{3}-\mathrm{c}_{4} & =236.76 \\
\mathrm{~s}_{7}-\mathrm{r}_{4}-\mathrm{b}_{4}-\mathrm{c}_{5} & =217.96 \\
\mathrm{~s}_{6}-\mathrm{r}_{5}-\mathrm{b}_{4}-\mathrm{d}_{4}-\mathrm{c}_{6} & =198.86 \\
\mathrm{~s}_{6}-\mathrm{r}_{5}-\mathrm{b}_{4}-\mathrm{c}_{7} & =183.09 \\
\mathrm{~s}_{5}-\mathrm{r}_{4}-\mathrm{b}_{3}-\mathrm{c}_{8} & =155.44 \\
\mathrm{~s}_{3}-\mathrm{r}_{3}-\mathrm{b}_{1}-\mathrm{d}_{2}-\mathrm{c}_{9} & =185.50 \\
\mathrm{~s}_{1}-\mathrm{r}_{1}-\mathrm{b}_{2}-\mathrm{d}_{3}-\mathrm{c}_{10}=210.30
\end{array}
$$$$
\sum \Rightarrow 2009.30
$$

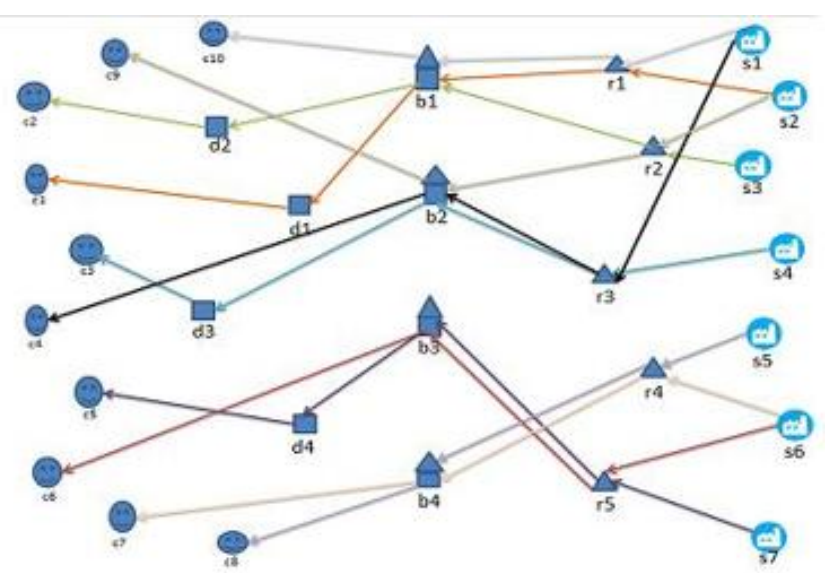

Fig. 4. Route choices for solution -1

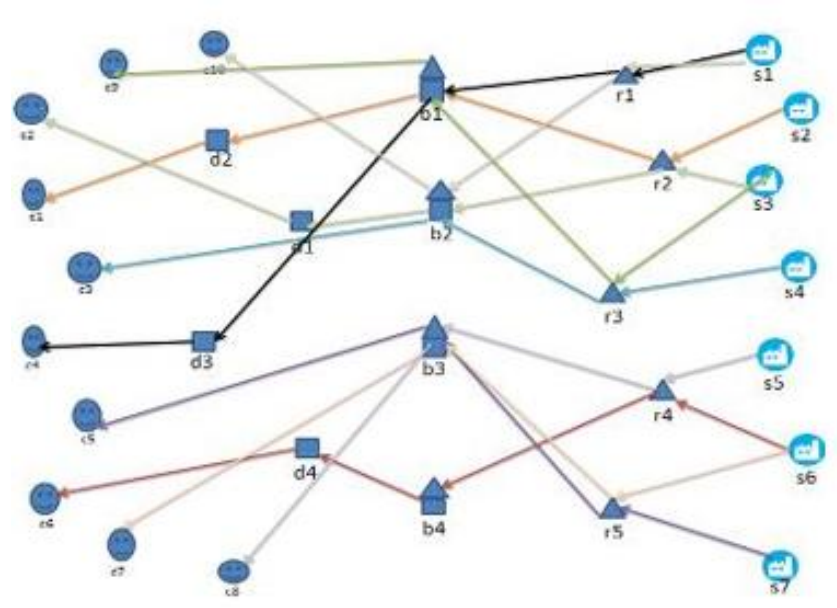

Fig. 5. Route choices for solution -2

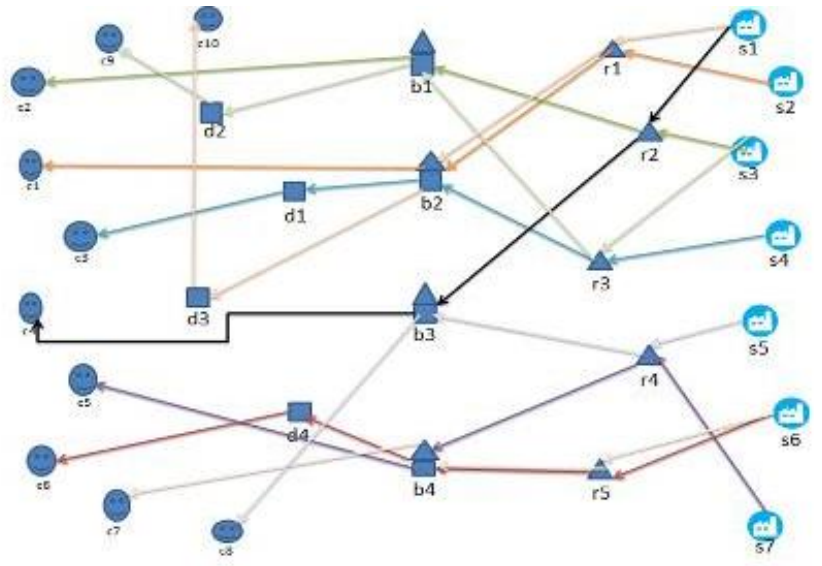

Fig. 6. Route choices for solution - 3

\section{RESULT}

A number of problem instances is generated for different ordered products by customer sizes and resources' availabilities. Table 4 summarizes the main properties of the randomly generated problem instances. We assume that a customer ordered the product from the availability of supplier that shows how the product is delivery to the customer.

Table-IV: Problem parameter value scenarios instance feature

\begin{tabular}{|l|l|}
\hline Features & Scenarios \\
\hline Number of customer & Up to 10 customer \\
\hline Number of supplier & Up to 7 supplier \\
\hline Number of receiving centre & Up to 5 receiving centre \\
\hline Number of both centre $(\mathrm{r}$ \& d) & Up to 4 both centre $(\mathrm{r}$ \& d) \\
\hline Number of distribution centre & Up to 4 distribution centre \\
\hline
\end{tabular}

The model is solved using various methodologies discussed in the previous chapter. The results are explained here to compare the performance of those methodologies. Table- $\mathrm{V}$ shows that the results on shortest distribution instances. The objective value of min TC is matched against with each methodology and the computation time to arrive the solution is also compared.

Table- V: Results on shortest distribution instances

\begin{tabular}{|c|ccc|c|ccc|cc|c|}
\hline \multicolumn{10}{|c|}{ Problem Instances } & \multicolumn{10}{|c|}{ Shortest path } \\
\hline SIze & $\boldsymbol{c}$ & $\boldsymbol{s}$ & $\boldsymbol{R}$ & $\boldsymbol{b}(\mathrm{r}, \boldsymbol{d})$ & $\begin{array}{c}\text { Lower } \\
\text { bound } \\
\text { solutions }\end{array}$ & CPLEX & \% gap & $\begin{array}{c}\text { Route } \\
\text { Selectlon } \\
\text { Heuristic }\end{array}$ & $\%$ gap \\
\hline Small & 4 & 3 & 3 & 2 & 2 & 380 & 395 & 3.95 & 424 & 11.58 \\
Small & 10 & 7 & 5 & 4 & 4 & 1879 & 1986 & 5.69 & 2048 & 11.17 \\
\hline Small & 15 & 10 & 8 & 5 & 5 & 2183 & 2300 & 5.36 & 2684 & 22.92 \\
Large & 100 & 60 & 40 & 50 & 45 & 18932 & 19963 & 5.45 & 22371 & 18.17 \\
\hline
\end{tabular}

\section{A. Discussion}

Overall the following observation has made

It seems very hard to optimally solve more than 15 customers by manually with in the time limit of three hours (which is large

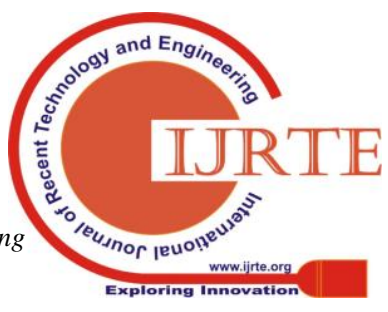


when compared to the CPLEX computation time). Even though the heuristic produced result is slower than the CPLEX the value is not optimal. In fact, the result from the heuristic solution methodology is makes complexity. It is clear from the results obtained from above that the CPLEX obtains the optimal solution but the computational time for the CPLEX solves in shortest time in our case the product ordered by the customer is to take the shortest path distribution decision.

The Route Selection Heuristic developed earlier solves the problem slower and the solution quality is poor. The optimal and feasible solution from the heuristically developed is not easy to find. CPLEX obtains an optimal solution for these large problems but the computational time is not affordable. So, a metaheuristic has to be developed in order to find solutions nearer to the global optimum computationally fast at the same time

\section{CONCLUSION}

A mathematical model is formulated for the e-commerce supply chain distribution problem. This model is useful to the industrial goods like (machinery and equipment) and consumer goods like (electronics, furniture) ordering the by customer the product availability of the supplier will be delivered through the shortest route to meet the minimum distribution cost or transportation cost. Also, this model takes into the account the time needed to the delivery of the products from the suppliers before being prepared to the shortest route to the customers. The objective was to minimize the total cost or distribution cost of each products. For the small scale and large-scale instances of problem, different solution methodologies were formed and solved. Various computational experiments have been performed for each of the proposed methodology.

\section{REFERENCES}

1. Ligang Cui , LinWang, Jie Deng, Jinlong Zhang "Intelligent algorithms for a new joint replenishment and synthetical delivery problem in a warehouse centralized supply chain" Knowledge-Based Systems, vol. 90, pp. 185-198, 2015.

2. Moueen K. Salameh, Ali A. Yassine, BacelMaddah, LikaaGhaddar "Joint replenishment model with substitution" Applied Mathematical Modelling, vol. 38, pp. 3662-3671, 2014.

3. CiroAlbertoAmayan, JimmyCarvajal, FabianCastano "A heuristic framework based on linear programming to solve the constrained ] joint replenishment problem (C-JRP)" Int. J. Production Economics Vol. 144, pp. 243-247, 2013.

4. Moshe Dror, Bruce C. Hartman, Wei Chang "The cost allocation issue in joint replenishment" Int. J. Production Economics, vol. 135, pp. 242-254, 2012.

5. Lin Wang, Cai-Xia Dun, Wen-Jie Bi, Yu-Rong Zeng “An effective and efficient differential evolution algorithm for the integrated stochastic joint replenishment and delivery model" Knowledge-Based Systems, vol. 36,pp. 104-114, 2012.

6. Lin Wang, Jing $\mathrm{He}$, Desheng Wu, Yu-Rong Zeng "A novel differential evolution algorithm for joint replenishment problem under interdependence and its application" Int. J. Production Economics, vol. 135 pp. 190-198, 2012.

7. Moutaz Khouja, Suresh Goyal "A review of the joint replenishment problem literature: 1989-2005" European Journal of Operational Research, vol.186, pp. 1-16, 2008.

8. G.Iassinovskaia S. Limbourg, and F. Riane "The inventory-routing problem of returnable transport items with time windows and simultaneous pickup and delivery in closed-loop supply chains" Int. J. Prod Econ, vol. 183, pp. 570-582, 2017.
9. L.L. Fu, M. A. Aloulou, and C. Triki, "Integrated production scheduling and vehicle routing problem with job splitting and delivery time windows.” Int. J. Prod. Res., vol. 55, no. 20, pp. 5942-5957, 2017.

10. R. Hlioui, A. Gharbi and A. Hajji, "Joint supplier selection, production and replenishment of an unreliable manufacturing- oriented supply chain,” Int. J. Prod. Econ., vol. 187, pp. 53-67, 2017.

11. A. Gharaei and F. Jolai, "A multi-agent approach to the integrated production scheduling and distribution problem in multi-factory supply chain,” Appl. Soft Comput J., vol. 65, pp. 577-589, 2018.

12. S. K. Paul, S. Asian, M. Goh and S. A. Torabi "Managing sudden transportation disruption in supply chains unfer delivery delay and quantity loss,” Ann. Oper. Res., vol. 273, no. 1-2, pp. 783-814, 2019.

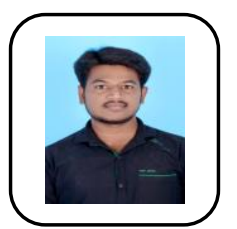

\section{AUTHORS PROFILE}

C. Pradeepkumar is graduate in Automobile Engineering, then did a post graduate on Manufacturing Engineering at Thiagarajar Engineering College. Presently he is Research Scholar in the Department of Automobile Engineering, Kalasalingam Academy of Education and Research, Virudhunagar District, Tamilnadu, India.

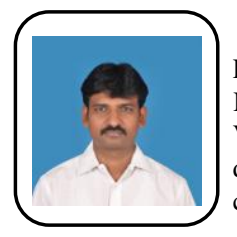

Dr. S. KARTHIKEYAN is working as Associate Professor in the Department of Automobile Engineering, Kalasalingam Academy of Education and Research, Virudhunagar District, Tamilnadu, India. He is currently doing active research in the area of Tribology of natural composite materials. His other areas of interest include characterization of materials and Supply Chain Management.

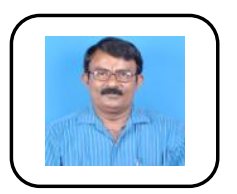

Dr. N. Jawahar is working as Professor in the Department of Mechanical Engineering, Ramco Institute of Technology, Rajapalayam, Virudhunagar District, Tamilnadu, India. 